DOI: https://doi.org/10.24843/MATRIK:JMBK.2018.v12.i01.p04

\title{
MANAJEMEN PENGETAHUAN DAN KEMAMPUAN LINTAS BUDAYA SERTA PENGARUHNYA TERHADAP ADAPTABILITAS ORGANISASI
}

\author{
Pudjo Sugito(1) \\ Sumartono $^{(2)}$ \\ ${ }^{(1),(2)}$ Fakultas Ekonomi dan Bisnis Universitas Merdeka Malang \\ email: pudjo.sugito@unmer.ac.id
}

\begin{abstract}
ABSTRAK
Tujuan dari penelitian ini adalah untuk menganalisis pengaruh manajemen pengetahuan dan kemampuan lintas budaya terhadap kemampuan beradaptasi organisasi. Populasi penelitian adalah industri kecil dan menengah di Malang, yaitu sebesar 279103 unit (Dinas Koperasi dan UKM, 2015). Teknik pengumpulan data yang digunakan adalah proportional random sampling yaitu sampel unit yang dipilih berdasarkan pertimbangan tertentu untuk mendapatkan sampel dengan karakteristik tertentu. Jumlah responden dalam penelitian ini adalah 200 responden yang berkinerja baik, sebagai persyaratan minimum yang dibutuhkan dalam teknik analisis data Structural Equation Model (SEM). Teknik analisis yang digunakan dalam penelitian ini adalah (1) analisis faktor, digunakan untuk mengkonfirmasi faktor-faktor yang paling dominan dalam satu kelompok variabel dan (2) bobot regresi pada SEM, digunakan untuk confirmatory memeriksa seberapa besar hubungan antar variabel. Berdasarkan hasil analisis data diketahui bahwa manajemen pengetahuan dan kemampuan lintas budaya berpengaruh secara signifikan terhadap kemampuan beradaptasi organisasi.
\end{abstract}

Kata kunci: manajemen pengetahuan, kemampuan lintas budaya, kemampuan beradaptasi organisasi

\begin{abstract}
The aim of this research is to analyze the effect of knowledge management and cross cultural ability to the organizational adaptability. The research population are small and medium industries in Malang, amounting to 279103 units (the Department of Cooperatives and SMEs, 2015). Data collection techniques was used proportional random sampling that is a unit sample selected based on certain considerations in order to obtain samples with specific characteristics. The number of respondents in this research determined the 200 respondents who are performing well, as a minimum requirement that is needed in data analysis techniques Structural Equation Model (SEM).Aanalysis techniques in this research were (1) factor analysis, is used to confirm the factors most dominant variable in one group and (2) regression weight in SEM, used for confirmatory examine how much the relationship between variables. Based on the results of data analysis revealed that knowledge management and cross cultural ability significantly effect to the organizational adaptability.

Keywords: knowledge management, cross cultural competence, organizational adaptability
\end{abstract}

\section{PENDAHULUAN}

Era perubahan teknologi informasi yang relatif cepat, telah memunculkan berbagai peluang usaha. Peluang ini memberikan persaingan pasar yang semakin kompetitif. Perubahan ini terus berlangsung semakin cepat diiringi banyaknya deregulasi yang terjadi baik ditingkat nasional maupun ditingkat internasional. Implikasinya, memunculkan persaingan yang ketat dalam memanfaatkan peluang-peluang usaha tersebut serta memunculkan paradigma dalam berkompetisi yang ditentukan oleh kemampuan berdaptasi secara institusional (Hana, 2013); (Martin et al. 2013). Nouruzy et al. (2013), mengungkapkan perlunya tata kelola pengetahuan untuk membangun adapatabilitas instiusional, sementara itu, Sugito (2015) menyatakan pentingnya kemampuan memahami perbedaan budaya untuk suksesnya setiap entitas bisnis.

Meningkatnya volatilitas pasar, ambiguitas informasi, ketidakjelasan batas-batas perusahaan dan industri, meningkatnya perhatian pada lingkungan ekologi dan sosial serta perubahan struktur organisasi, kultur dan nilai-nilai, kian menuntut oganisasi bisnis terutama yang berskala kecil menengah harus mempunyai adaptibilitas institusional yang memadai. Adaptabilitas harus dibangun melalui kemampuan organisasional yang harus di up date secara periodik. Tujuan penelitian ini untuk menganalisis pengaruh manajemen pengetahuan dan kemampuan lintas budaya 
terhadap adaptabilitas organisasi. Manfaat penelitian diharapkan berguna pada usaha kecil menengah untuk membangun adaptabilitas agar tetap eksis dan berkembang pada era perubahan. Kemampuan adaptabilitas organisasional tersebut, maka usaha kecil menengah akan makin kompetitif sekaligus menjadi multiplier effect terhadap peningkatan kesejahteraan masyarakat.

Adaptabilitas organisasi berkaitan dengan kemampuan sebuah organisasi untuk berimprovisasi menyesuaikan diri dengan struktur dan proses bisnis yang kemudian sukses mencapai tujuannya pada lingkungan yang berubah dinamis. Sebuah kemampuan yang mutlak harus dimiliki oleh setiap organisasi, terutama entitas bisnis yang kini cenderung menuju pada the fasting changing era. Jika tidak, organisasi tersebut akan mengalami kemunduran kinerja menuju pada kebangkrutan.

Pada pendekatan tradisional, merancang sebuah strategi berkompetisi selalu berasumsi bahwa segala sesuatu bersifat stabil. Banyak entitas bisnis bertujuan membangun keunggulan konpetitif dengan menggunakan skala ekonomi, memanfaatkan celuk pasar atau dengan mengeksploitasi kecakapan tertentu dan sumberda daya ekonomi lainnya. Tetapi globalisasi, teknologi baru, dan makin tingginya iklim transparansi telah saling berintegrasi satu dengan lainnya dan membetuk lingkungan bisnis. Keunggulan kompetitif yang berkelanjutan tidak lagi muncul dari positioning atau sumberdaya. Reevers and Deimler (2011) berpendapat berasal dari 4 (empat) kemampuan organisasi yang dapat memacu kemampuan adaptasi, antara lain (a) kemampuan membaca dan bereaksi pada sinyal perubahan., (b) kemampuan melakukan eksperimen berkala dan cepat., (c) kemampuan mengelola sistim yang kompleks dan saling terkoneksi dan (d) Kemampuan memotivasi pekerja dan mitra kerja. Selanjutnya, pada jurnal berkala Harvard Business Review $(H B R)$ sebuah artikel tetang Adaptation: The New Competitive Advantage, Reeves dan Deimler (2013) mengungkapkan empat kemampuan organisasi yang dapat meningkatkan kemampuannya untuk beradaptasi, The Ability to Read and Act on Signal, The Ability to Experiment, The Ability to Manage Complex Systems and The Ability to Mobilize

Beberapa penelitian antara lain Kosasih dan Budiani (2008) mengungkapkan bahwa manajemen pengetahuan sebagai kemampuan yang sangat berpengaruh terhadap adaptabilitas organisasi. Maknanya, untuk membangun kemampuan organisasi dalam beradaptasi pada dinamika perubahan mutlak memerlukan manajemen pengetahuan. Konsep knowledge management menjadi guidance tentang pengelolaan intangible assets yang menjadi pilar perusahaan dalam menciptakan nilai (dari produk/jasa/solusi) yang ditawarkan perusahaan kepada pelanggannya. Pemahaman mengenai nilai buku perusahaan harus disertai dengan pemahaman nilai intangible assets perusahaan. Sedangkan jenis penerapan pengelolaan knowledge management ada dua, yaitu (a) Tacit Knowledge, yang pada dasarnya tacit knowledge bersifat personal, dikembangkan melalui pengalaman yang sulit untuk diformulasikan dan dikomunikasikan (Carrillo et al., 2007). Berdasarkan pengertiannya, maka tacit knowledge dikategorikan sebagai personal knowledge atau dengan kata lain pengetahuan yang diperoleh dari individu (perorangan). Menurut Bahm (2008) penelitian pada sifat dasar pengetahuan seketika mempertemukan perbedaan antara knower dan known, atau seringkali diartikan dalam istilah subject dan object, atau ingredient subjective dan objective dalam pengalaman. Pengalaman yang diperoleh tiap karyawan tentunya berbeda-beda berdasarkan situasi dan kondisi yang tidak dapat diprediksi. Definisi experience yang diambil dari kamus bahasa Inggris adalah the process of gaining knowledge or skill over a period of time through seeing and doing things rather than through studying. (b) Explicit knowledge, manajemen pengetahuan bersifat formal dan sistematis yang mudah untuk dikomunikasikan dan dibagi (Carrillo et al., 2007). Penerapan explicit knowledge ini lebih mudah karena pengetahuan yang diperoleh dalam bentuk tulisan atau pernyataan yang didokumentasikan, sehingga setiap karyawan dapat mempelajarinya secara independent. Explicit knowledge dalam penelitian ini adalah job procedure dan technology. Job procedure adalah tanggung jawab atau tugas yang bersifat formal atau perintah resmi atau cara melakukan suatu hal. Berdasarkan pernyataan Anshori (2015) selaku pihak yang mencetuskan knowledge management, salah satu bentuk konkret dari explicit knowledge adalah Standard Operation Procedure. Standard Operation Procedure atau prosedur pelaksanaan dasar dibuat untuk mempertahankan kualitas dan hasil kerja, dimana tugas-tugas akan semakin mudah dikerjakan dan tamu akan terbiasa dengan sistem pelayanan yang ada. Teknologi merupakan salah satu elemen pokok yang terdapat pada knowledge management, dikenal sebagai media yang mempermudah penyebaran explicit knowledge. Salah satu 
teknologi paling mutakhir yang saat ini digunakan oleh banyak perusahaan untuk proses penyebaran knowledge adalah intranet, dimana hal ini didasarkan pada kebutuhan untuk mengakses knowledge dan melakukan kolaborasi, komunikasi serta sharing knowledge secara on line.

Beberapa hasil riset diantaranya diungkapkan Noruzy et al. (2013) dan Omotayo(2015) bahwa manajemen pengetahuan menjadi faktor penentu kemampuan adaptabilitas organisasi. Peneliti lain, Edoun (2016) menyatakan bahwa manajemen pengetahuan berdampak positip pada inovasi dan adaptabilitas. Temuan riset tersebut diperkuat hasil penelitian Utami et al. (2016) yang dilakukan pada lembaga keuangan bahwa menejemen pengetahuan mendorong inovasi dan adaprabilitas. Nwaiwu and Imavidon (2017) menyatakan bahwa manajemen pengetahuan menjadi variabel moderasi pada terwujudnya kemampuan adaptasi dan keberlangsungan sebuah organisasi.

Davies, et al. (2013) mengungkapkan bahwa kemampuan lintas budaya yang merupakan kemampuan untuk beroperasi dalam pengaturan budaya yang berbeda diperlukan bagi setiap entitas bisnis. Dalam dunia yang benar-benar terhubung secara global, seorang pekerja dengan keahlian tertentu bisa diposting di sejumlah lokasi. Tentunya harus mampu beroperasi dalam lingkungan apapun yang mereka tempati, hal ini menuntut konten specifik, seperti keterampilan linguistik, tetapi juga kemampuan beradaptasi terhadap perubahan keadaan dan kemampuan untuk merasakan dan merespon konteks baru. Kemampuan lintas budaya akan menjadi keterampilan penting bagi semua pekerja, bukan hanya yang memiliki untuk beroperasi di lingkungan geografis yang beragam. Banyak riset mendapatkan bahwa apa yang membuat kelompok yang benar-benar cerdas dan inovatif adalah kombinasi dari berbagai usia, keterampilan, disiplin dan kerja serta gaya berpikir. Kemajuan sangat bergantung pada perbedaan kolektif seperti misal pada skor IQ individual. Keanekaragaman akan menjadi kemampuan inti bagi organisasi pada dekade berikutnya. Karyawan yang sukses dalam tim-tim yang beragam harus mampu mengidentifikasi dan mengkomunikasikan titik koneksi yang melampaui perbedaan dan memungkinkan untuk membangun hubungan efektif. Selanjutnya, Okoro (2013) pada hasil risetnya mengungkapkan bahwa kemampuan lintas budaya dapat memicu adaptibilitas institusional. Riset ini dilakukan pada manajer ekspatriat China yang dikirim ke luar negara China. Temuan-temuan tersebut diperkuat Gunanto dan Gusti (2014) dan Luthfia (2014), bahwa pemahaman lintas budaya berpengaruh terhadap kemampuan beradaptasi. Puspitasari dan Musadieq (2014) juga mengungkapkan bahwa kepemimpinan yang memahami nilai-nilai lintas budaya lebih mampu memiliki adaptabilitas pada lingkungan pasar baru. Oleh karena itu, berdasarkan beberapa temuan riset tersebut, dan juga tujuan penelitian, tinjauan pustaka, serta kerangka pikir teoritis pada penelitian ini, maka rumusan hipotesisnya adalah sebagai berikut:

$\mathrm{H}_{1}$ : Manajemen pengetahuan berpengaruh signifikan terhadap adaptabilitas organisasi.

$\mathrm{H}_{2}$ : Kemampuan lintas budaya berpengaruh signifikan terhadap adaptabilitas organisasi.

\section{METODE PENELITIAN}

Kegiatan penelitian ini adalah penelitian penjelasan (explanatory research) dengan metode kuantitatif. Pengumpulan data yang digunakan adalah teknik survei, suatu kajian yang mengambil sampel dari satu populasi dengan menggunakan kuesioner sebagai alat pengumpul data pokok. Unit analisisnya, semua pelaku UKM di wilayah Malang Raya. Berdasarkan sifat hubungannya dengan variabel lain, terdiri dari variabel eksogen dan variabel endogen. Pada penelitian ini manajemen pengetahuan dan kemampuan lintas budaya sebagai variabel eksogen dan sebagai variabel endogennya adalah adaptibilitas organisasi. Berdasarkan telaah pustaka maka difinisi operasional variabel penelitian ini adalah (1) Manajemen pengetahuan adalah sebuah kemampuan untuk memahami konsepkonsep yang bersifat lintas berbagai disiplin keilmuan/pekerjaan., (2) Kemampuan lintas budaya adalah kemampuan organisasi untuk beroperasi dalam pengaturan budaya yang berbeda., (3) Adaptabilitas organisasi adalah kemampuan sebuah organisasi untuk berimprovisasi menyesuaikan diri dengan struktur dan proses bisnis yang kemudian sukses mencapai tujuannya pada lingkungan yang berubah dinamis.

Jenis data yang digunakan pada penelitian ini adalah data primer, yang diperoleh secara langsung dari para responden penelitian (pelaku UKM). Data primer pada penelitian ini diperoleh dari jawaban yang didapat dari kuesioner yang sudah valid dan realibel, yang diberikan kepada responden penelitian. Pada penelitian ini terdapat 10 indikator. Populasi pada penelitian ini adalah semua pelaku UKM di Wilayah Malang Raya yang berjumlah 6.050 unit Kota Batu, 273.000 unit Kabupaten Malang dan 1053 Kota Malang (Dinas Koperasi dan UKM, 2013). 
Mengingat jumlah responden yang relatif besar dan untuk mengantisipasi adanya data yang cacat, teknik pengumpulan data yang digunakan adalah proportional random sampling yaitu sebuah satuan sampel yang dipilih berdasarkan pertimbangan tertentu dengan tujuan untuk mendapatkan sampel dengan karakteristik tertentu. Menurut Sugiyono (2009), responden yang representatif pada teknik analisis SEM adalah 100-200 responden. Jumlah responden penelitian ini ditentukan 200 responden, sebagai syarat analisis SEM.

Pada penelitian ini data yang dikumpulkan menggunakan daftar pertanyaan atau kuesioner. Kuesioner merupakan cara pengumpulan data dengan memberikan daftar pertanyaan kepada responden untuk diisi. Pertanyaan-pertanyaan yang terdapat di dalam kuesioner dibuat dalam bentuk pertanyaan dengan menggunakan skala 1-10 dari sangat tidak setuju sampai sangat setuju. Teknik analisis data yang digunakan adalah Structual Equation Model (SEM) (Ferdinand, 2009). Secara bertahap menggunakan dua macam teknik analisis, (a) factor analysis pada SEM, digunakan untuk mengkonfirmasikan faktor-faktor yang paling dominan dalam satu kelompok variabel dan (b) regression weight pada SEM, digunakan untuk confirmatory meneliti seberapa besar hubungan antar variabel.

\section{HASIL DAN PEMBAHASAN Analisis Diskriptif}

Analisis diskriptif merupakan sebuah analisis yang bertujuan mendiskripsikan persepsi responden pada semua variabel penelitian. Adapun rerata pendapat responden untuk adaptabilitas organisasi bersaing, manajemen pengetahuan dan kemampuan lintas budaya yang direkapitulasi dari hasil kuesioener yang disebarkan pada 200 responden UKM di wilayah Malang Raya disajikan pada Gambar 2.

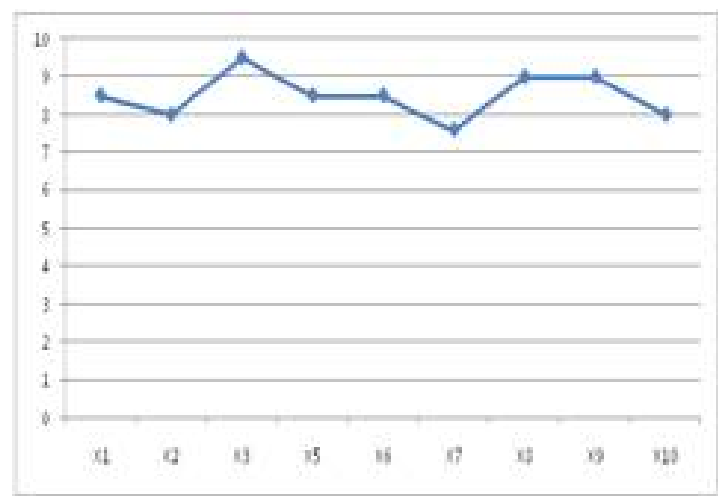

Gambar 2. Rerata Tanggapan Responden Sumber: Data Primer Diolah, 2016
Berdasarkan Gambar 2 terlihat bahwa pendapat 200 responden terhadap indikator-indikator variabel penelitian berkisar antara diatas 7 sampai mendekati 10. Maknanya, semua responden memberikan jawaban mendekati sangat setuju, yang berarti memberikan respon positip terhadap pentingnya manajemen pengetahuan, kemampuan lintas budaya dan adaptabilitas organisasi pada tata kelola entitas usaha kecil. Dengan kata lain, entitas usaha kecilpun memerlukan tata kelola dengan memanfaatkan menejemen pengetahuan, yang selama ini hanya banyak dimanfaatkan entitas usaha berskala besar. Bahkan, terus berlangsungnya globalisasi ekonomi yang menjadikan batas-batas ekonomi negara makin hilang tentu tuntutan dalam memahami budaya yang berbeda sangat diperlukan. Hal itu karena budaya tidak bisa dinilai baik dan buruk, melainkan hanya berbeda satu dengan lainnya.

\section{Analisis Inferensial}

\section{Model Keterkaitan Manajemen Pengetahuan, Kemampuan Lintas Budaya dan Adaptabilitas Organisasi}

Analisis measurement model dianalisis melalui Confirmatiory Factor Analysis dapat dilihat bahwa masing-masing variabel dapat digunakan untuk mendefinisikan sebuah konstruk laten, maka sebuah model SEM dapat dianalisis. Pada bagian ini menyajikan hasil pengolahan dan analisis data dengan Structural Equation Modeling (SEM), dimana uji kesesuaian dan uji statistik akan dilakukan. Hasil pengolahan data untuk analisis model penuh SEM ditampilkan pada Gambar 3.

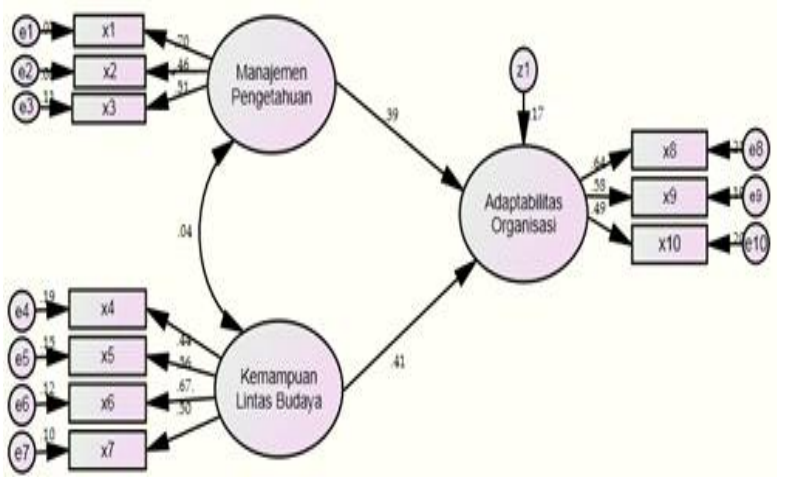

Gambar 3. Model Structural Equation Modelling Sumber: Data Primer Diolah, 2016

Pengujian Structural Equation Modeling (SEM) dilakukan dengan dua macam pengujian yaitu uji kesesuaian model (goodness-of-fit) serta uji signifikansi kausalitas melalui uji koefisien regresi seperti yang diuraikan pada bagian berikut ini. 
Berdasarkan hasil olah data yang dilakukan terungkap bahwa pengujian modal yang menggunakan indeks kesesuaian terungkap bahwa semua indeks dapat dinyatakan baik. Sehingga model yang dirumuskan dinyatakan diterima.

\section{Uji Kriteria Goodness-of-Fit}

Pengujian model ini menggunakan beberapa fit indeks untuk mengukur seberapa kesesuaian dari model penelitian yang sedang dikembangkan. Dari analisis AMOS 22.0 diperoleh hasil sebagai Tabel 1.

Tabel 1. Goodness-of-Fit Index

\begin{tabular}{llll}
\hline Goodness of Fit Index & Cut-off Value & Hasil Analisis & Evaluasi Model \\
\hline $\mathrm{X}^{2}$ - Chi-square & $\mathrm{P}=5 \%$, Chi-Square & 20.940 & Baik \\
& 68.6732 & & \\
\hline Signifinacance Probability & $\geq 0.05$ & 0.274 & Baik \\
\hline RMSEA & $\leq 0.08$ & 0.023 & Baik \\
\hline GFI & $\geq 0.90$ & 0.971 & Baik \\
\hline AGFI & $\geq 0.90$ & 0.987 & Baik \\
\hline CMIN/DF & $\leq 2.00$ & 1.003 & Baik \\
\hline TLI & $\geq 0.95$ & 0.981 & Baik \\
\hline CFI & $\geq 0.95$ & 0.967 & Baik \\
\hline
\end{tabular}

Sumber: Hasil Olah Data Primer, 2016

Uji kesesuaian dilakukan untuk mengetahui indeks kesesuaian (fit index) atas proporsi tertimbang dari varian dalam matriks kovarian sampel. Uji terhadap hipotesis model menunjukkan bahwa model ini sesuai dengan data yang tersedia seperti terlihat dari tingkat signifikansi terhadap $\mathrm{Chi}$ Square model ini sebesar 20.940. Nilai probalility sebesar 0,274 menunjukkan tidak adanya perbedaan yang signifikan antara matriks kovarians data dengan matriks kovarian yang diestimasi. Nilai probability pada analisis ini menunjukkan nilai diatas batas signifikansi 0,05. Hal ini diartikan bahwa hipotesis nol yang menyatakan tidak berbedanya matrik kovarians. Sampel dan matrik kovarians populasi yang diestimasi dapat diterima.

Besarnya nilai Goodness of Fit $(\mathrm{GFI})=0,971$. Adapun nilai GFI ini merupakan ukuran non statistical yang mempunyai nilai rentang antara 0 (poor fit) sampai dengan 1 (perfect fit). Untuk menguji lebih lanjut nilai GFI, Fit Index diatas selanjutnya di-adjust terhadap Degrees of Freedom yang tersedia. Hasil dari pengolahan data Adjusted Goodness of Fit Index (AGFI) adalah 0,987. Hasil uji kesesuaian dari model diatas tidak memenuhi (marjinal) untuk persyaratan batas GFI > 0.90 dan tidak memenuhi (marjinal) untuk persyaratan AGFI $>$ 0.90. Meskipun demikian, secara umum model penelitian memiliki tingkat Goodness of Fit yang dapat diterima. Fakta-fakta tersebut memiliki arti bahwa model menunjukkan hasil uji yang baik pada model penuh.

\section{Uji Kausalitas: Regression Weight}

Dalam uji statistik, hubungan antar variabel yang menjadi dasar dalam hipotesis penelitian telah diajukan. Untuk menguji hipotesis mengenai kausalitas yang dikembangkan dalam model ini, perlu diuji hipotesis nol yang menyatakan bahwa koefisien regresi antara hubungan adalah sama dengan nol melalui uji-t yang lazim dalam model-model regresi. Uji statistik hasil pengolahan dengan SEM dilakukan dengan melihat tingkat signifikansi hubungan antar variabel yang ditunjukkan melalui nilai Probability $(P)$ dan Critical Ratio (CR) masing-masing hubungan antar variabel pada Tabel 2.

Tabel 2. Regression Weight

\begin{tabular}{lllllll}
\hline & & & Estimate & S.E. & C.R. & P \\
\hline Adapatibilitas Org. & $<---$ & Manajemen pengetahuan & .39 & .037 & 10.32 & .002 \\
\hline Adaptabilitas Org. & $<---$ & $\begin{array}{l}\text { Kemampuan Lintas } \\
\text { budaya }\end{array}$ & .41 & .035 & 11.71 & .035 \\
\hline
\end{tabular}

Sumber: Hasil Olah Data Primer, 2016

Pada Tabel 2 terlihat bahwa semua koefisien regresi secara signifikan tidak sama dengan nol, karena itu hipotesa nol bahwa regression weight adalah sama dengan nol dapat ditolak, untuk menerima hipotesis alternatif bahwa masing-masing hipotesis mengenai hubungan kausalitas yang disajikan dalam model itu dapat diterima.

\section{Pengujian Hipotesis}

Pengujian hipotesis digunakan untuk menguji beberapa hipotesis penelitian seperti yang telah 
dirumuskan sebelumnya. Pengujian hipotesis didasarkan atas pengolahan data penelitian dengan menggunakan teknik analisis SEM, dengan cara menganalisis nilai regresi seperti yang ditampilkan pada tabel sebelumnya. Pengujian hipotesis dilakukan dengan menganalisis nilai $\mathrm{CR}$ dan nilai $\mathrm{P}$ pada hasil oleh data Regresion Weights Full Model, dibandingkan dengan batas statistik yang disyaratkan, yaitu nilai di atas 2.00 untuk nilai CR dan dibawah 0.05 untuk nilai $P$.

\section{Uji Hipotesis 1}

Hipotesis 1 : Manajemen pengetahuan berpengaruh signifikan terhadap adaptabilitas organisasi. Berdasarkan tabel 2 terungkap bahwa nilai CR sebesar 10,32 lebih besar dari 2.00 dengan nilai $p$ sebesar 0,002 yang berarti $<0.05$. Dengan demikian $\mathrm{H} 1$ pada penelitian ini dapat diterima. Temuan riset ini sejalan dengan pendapat Anshori (2005), juga Kosasih dan Budiani (2008) serta Gao and Clarke (2008). Bahwa manajemen pengetahuan berperan penting dalam mewujudkan kemampuan entitas organisasi pada dinamika perubahan. Selain itu, memperkuat hasil riset Amayah (2013) bahwa menejemen pengetahuan sebagai determinan penentu keberhasilan pasar. Penelitian ini sejalan dan melengkapi pendapat Bosua and Venkitachalam (2013) bahwa manajemen pengetahuan berkontribuasi pada terbentuknya networking. Penelitian ini juga mendukung penelitian Budiastuti (2013) dan bahkan penelitian sebelumnya yang dilakukan Du Plessis (2007) yang mengungkapkan bahwa manajemen pengetahuan sebagai kemampuan yang sangat berpengaruh terhadap adaptabilitas organisasi. Hasil penelitian yang memperkaya temuan Edoun (2016) yang dilakukan pada sektor publik bahwa manajemen pengetahuan menjadi faktor pendorong keberlangsungan organisasi yang dimediasi oleh adaptabilitas organisasi. Dengan demikian, menejemen pengetahuan dapat dinyatakan sebagai komponen penting bagi setiap organisasi untuk bisa tetap eksis pada era perubahan akhir-akhir ini dan tentu temuan riset ini telah memperkaya khasanah keilmuan manajemen.

\section{Uji Hipotesis 2}

Hipotesis 2 : komepetensi lintas budaya berpengaruh signifikan terhadap keunggulan bersaing. Berdasarkan Tabel 2 terungkap bahwa dengan nilai CR sebesar 11.71 lebih besar dari 2.00 dengan nilai p sebesar 0,035 yang berarti < 0.05. Dengan demikian $\mathrm{H} 2$ pada penelitian ini dapat diterima. Temuan ini mendukung pendapat
Hise and Choi (2011) bahwa kemampuan adaptasi harus dibangun melalui kemampuan pemahaman berbagai budaya. Juga sejalan dengan ungkapan Moon and Park (2011) dan pernyataan Roy (2012) pada hasil penelitiannya bahwa kemampuan lintas budaya berkontribusi terhadap daya saing, utamanya manakala melakukan penetrasi pasar global, yang memiliki budaya berbeda. Juga, sejalan dengan temuan Hsieh et al. (2012) bahwa cross cultural competency menjadi determinan keberhasilan bisnis global. Selain itu, mendukung Davies, et al. (2013) yang mengungkapkan bahwa kemampuan lintas budaya yang merupakan kemampuan untuk beroperasi dalam pengaturan budaya yang berbeda diperlukan bagi setiap entitas bisnis. Juga, melengkapi temuan riset Gunanto, E. and Gusti, Y.K. (2014) bahwa kemampuan pemahaman lintas budaya menjadi kunci keberhasilan pemasaran internasional. Bahkan mendukung temuan Welsa, et al. (2017) bahwa pemahaman pada budaya daerah menjadi komponen penting pada bisnis rumah makan. Dengan demikian, kemampuan lintas budaya merupakan salah satu kunci sukses dalam meningkatkan adaptabilitas organisasi menuju menuju entitas bisnis yang berdaya saing.

\section{SIMPULAN DAN SARAN}

Berdasarkan hasil penelitian, terungkap bahwa manajemen pengetahuan berpengaruh signifikan terhadap kemampuan entitas usaha kecil dalam beradaptasi dengan era perubahan akhir-akhir ini. Hasil penelitian juga menunjukkan bahwa kemampuan lintas budaya berpengaruh nyata terhadap adapatabilitas organisasi. Maknanya, baik manajemen pengetahuan maupun kemampuan lintas budaya sangat diperlukan dalam rangka eksistensi dan berkembangnya usaha kecil, khususnya di wilayah Malang Raya.

Berdasarkan kesimpulan pada hasil penelitian ini maka dalam rangka terus memperkaya khasanah kelimuan manajemen, maka penelitian mendatang hendaknya lebih fokus pada indikatorindikator manajemen pengetahuan dan kemampuan lintas budaya. Hal itu karena luarannya akan lebih fokus dan detail, yang nantinya bukan hanya mempunyai manfaat teoritik, melainkan juga manfaat pragmatis yang bisa diapliksikan dalam menjadikan usaha kecil lebih mampu berdaptasi pada dinamika perubahan faktor-faktor makro yang belakangan ini cenderung makin cepat menuju pada datangnya the fasting changing era. 


\section{REFERENSI}

Anshori, Y.(2005), Analisis Keunggulan Bersaing Melalui Penerapan Knowledge Management dan Knowledge-Based Strategy di Surabaya Plaza Hotel, Jurnal Manajemen Perhotelan, 1(2): 39-53.

Amayah, A.T. (2013). Determinants of knowledge sharing in a public sector organisation, Journal of Knowledge Management, 17(3): 454-471,

Bellhouse W. (2011), Adaptibility dan The Competitive Advantage, Global Business Jurnal, 11(15): 180-190.

Bosua, R. and Venkitachalam, K. (2013). Aligning strategies and processes in knowledge management: a framework. Journal of Knowledge Management, 17(3): 331-346

Budiastuti, D. (2013), Pemahaman Mahasiswa terhadap Kondisi Manajemen Pengetahuan dan Manajemen Inovasi PTS di Jakarta, Binus Business Review, 4(2): 655-660

Carrillo, P.M. \& Chinowsky, P. (2006), Exploiting Knowledge Management: The Engering and Construction Perspective, Third Edition, ACE Publishing.

Davies, M. ; Fidler, I. \& Gorbis, M. (2013), Measurement of Knowledge: Process and Practice in Knowledge Management, Student Edition, Boston: McGraw-Hill Irwin.

Du Plessis, M. (2007). Knowledge management and what makes complex implementation successful? Journal of Knowledge Management, 11(2): 91-101.

Edoun, E.I.(2016), Impact of Knowledge Management in Public Sector Economy, International Journal of Management, 2(5): 67-77.

Ferdinand A., (2009), Structural Equation Modeling, Edisi revisi, Penerbit Salemba Empat, Jakarta

Gao, F., Li, M. and Clarke, S. (2008). Knowledge, management, and knowledge management in business operations. Journal of Knowledge Management, 12(2): 3-17,

Gunanto, E. \& Gusti, Y.K. (2014), Pengaruh Lintas Budaya pada Pemasaran Internasional dengan Pendekatan Perilaku Konsumen, Jurnal Riset Manajemen, 1(2): 168 - 176

Hana U., (2013), Competitive Advantage Achievement through Innovation and Knowledge, Journal of Competitiveness, 5(1): 82-96.

Hsieh, S.C., Lin, J.S. \& Lee, H.C. (2012), Analysis on Literature Review of Competency, International Review of Business and Economics, 2(2):.25-50.
Hise, R. and Choi, Y.T. (2011), Are Us Companies Employing Standardization Or Adaptation Strategies In Their International Markets? Journal of International Business and Cultural Studies, 4(^): 1-29.

Jeon, S., Kim, Y. and Koh, J. (2011). An integrative model for knowledge sharing in communitiesof-practice. Journal of Knowledge Management, 15(2): 251-269,

Kosasih, Ida and Budiani, Sri (2008), The Knowledge Management in The Creative Industries, Jurnal of International Business Studies (JIBS), 33(10): 345-355.

Luthfia, A. (2014), Pentingnya Kesadaran Antarbudaya dan Kemampuan Komunikasi Antarbudaya Dalam Dunia Kerja Global, Jurnal Humaniora, 5(1): 9-22

Martín G., Delgado M., Navas J.E. \& Cruz J., (2013). The moderating role of innovation culture in the relationship between knowledge assets and product innovation, Technological Forecasting and Social Change Journal, 2(1): 351-363.

Moon, T.W. and Park, S.I. (2011), The Effect of Cultural Distance on International Marketing Strategy: A Comparison of Cultural Distance and Managerial Perception Measures, Journal of Global Marketing, 24(9): 18-40.

Noruzy, A., Dalfard, V.M., Azhdari, B., NazariShirkouhi, S. \& Rezazadeh, A. (2013). Relationship between transformational leadership, knowledge management, organizational innovation and organizational performance, The International Journal of Advanced Manufacturing Technology, 2(6): 45-57.

Nwaiwu, J.C \& Imavidon, H.C. (2017), Knowledge Management and Organisational Survival: A Study of Telecommunication Industry in Port Harcourt, Nigeria, International Journal of Advanced Academic Research Social \& Management Sciences, 3(7): 110-1123.

Okoro E., (2013), International Organizations and Operations: An Analysis of Cross-Cultural Communication Effectiveness, Journal of Business \& Management, 1(1): 75-90.

Omotayo, F.O. (2015), Knowledge Management as an important tool in Organisational Management, Journal of Knowledge Management, 5(6): 125-134.

Pratama, I. \& Musadieq, M. (2016), Perlunya Pemahaman Lintas Budaya Dalam Proses Negosiasi Bisnis, Jurnal Administrasi Bisnis (JAB), 24(1): 1-10 
Puspitasari, I. \& Musadieq, M. (2014), Analisis Gaya Kepemimpinan Lintas Budaya Ekspatriat, Jurnal Administrasi Bisnis (JAB), 1(8): 1-10

Reeves, M. \& Deimler, M (2013), New Bases of Competitiva Advantage, Harvard Business Review, 1(5): 435-449.

Rejeki, N.S.(2007), Perbedaan Budaya dan Adaptasi Antarbudaya dalam Relasi Kemitraan IntiPlasma, Jurnal Ilmu Komunikasi, 4(2): 111-121.

Serenko, A, Bontis, N., Booker, L, Sadeddin, K. and Hardie, T. (2010). A scientometric analysis of knowledge management and intellectual capital academic literature (1994-2008). Journal of Knowledge Management, 14(1): 3-23.

Sugito, P. \& Kamaludin, (2016), Adaptabilitas dan Keunggulan Bersaing, Jurnal Manajemen dan Kewirausahaan, Vol 3, No. 1, FEB Unmer Malang.

Tian, K. and Borges, L. (2011), Cross-Cultural Issues in Marketing Communications: An
Anthropological Perspective of International Business, International Journal of China Marketing, 2(1): 200-212.

Utami, S.R. ; Ali, M. \& Nohong, M. (2016), The Implementation Strategy of Knowledge Management on the Employees of PT Bank Muamalat Indonesia Tbk Makassar Branch, Jurnal Analisis, 5(1) : $72-77$

Wang, S. and Noe, R. A. (2010). Knowledge sharing: A review and directions for future research. Human Resource Management Review, 20(2): 115-131.

Welsa, H. SuHarti \& Latifah, (2017), Budaya Minangkabau dan Implementasi pada Manajemen Rumah Makan Padang di Ygyakarta, Ekuitas: Jurnal Ekonomi dan Keuangan, 1(2): 181 - 203

Wexler, M. (2011). The who, what and why of knowledge mapping. Journal of Knowledge Management, 5(3): 249-263. 